\title{
Measuring upper limb function and patient reported outcomes after major breast cancer surgery: a pilot study in an Asian cohort
}

Kai Siang Chan ${ }^{1}$, Ding Zeng ${ }^{2}$, Joelle Hoi Ting Leung ${ }^{3}$, Belinda Si Yin Ooi ${ }^{4}$, Kit Teng Kong ${ }^{3}$, Yi Heng Yeo $^{3}$, Jerry Tiong Thye Goo ${ }^{3}$ and Clement Luck Khng Chia ${ }^{3^{*}}$

\begin{abstract}
Background: Breast cancer is the most common cancer in women worldwide. Major breast cancer surgery especially with axillary lymph node dissection (ALND), is associated with upper limb functional decline. Majority of studies are conducted in Western population and may not be applicable to Asians. This pilot study aims to evaluate whether major breast surgery results in upper limb functional impairment in a cohort of Asian women with breast cancer.

Methods: This is a prospective cohort study of 41 patients who underwent 44 major breast surgeries from April 2018 to August 2019. Main inclusion criteria were patients over 21 years of age undergoing major breast surgery for breast cancer. Major breast surgery was defined as wide local excision (WLE) or mastectomy. Main exclusion criteria were patients with pre-existing neurological or rheumatological co-morbidities affecting upper limb function or previous trauma with resulting deformities to the upper limbs. Patients underwent early rehabilitation from postoperative day 1. Shoulder flexion and abduction active range of motion (AROM) and QuickDASH disability score were assessed 1 week before surgery, post-operative week 2 and week 6 . Baseline demographics and peri-operative data were also collected.

Results: Median age was 62.5 years. There were 16 (36.4\%) wide local excisions and 28 (63.6\%) simple mastectomies. Two (4.5\%) cases had neoadjuvant chemotherapy. Fifteen (34.1\%) cases had ALND. At post-operative week 6, shoulder flexion was comparable to baseline $(p=0.775)$, while abduction improved from baseline $(p=0.016)$. However, QuickDASH disability score was significantly worse at post-operative week 6 compared to baseline (median score 2.5 vs $0, p=0.027$ ). Subgroup analysis of patients with ALND demonstrated significantly worse QuickDASH disability score at post-operative week $6(p=0.010)$ but not for patients with only sentinel lymph node biopsy $(p=0.396)$.

(Continued on next page)
\end{abstract}

\footnotetext{
* Correspondence: chia.clement.lk@ktph.com.sg

${ }^{3}$ Department of General Surgery, Khoo Teck Puat Hospital, Singapore, Singapore

Full list of author information is available at the end of the article
}

(c) The Author(s). 2020 Open Access This article is licensed under a Creative Commons Attribution 4.0 International License, which permits use, sharing, adaptation, distribution and reproduction in any medium or format, as long as you give appropriate credit to the original author(s) and the source, provide a link to the Creative Commons licence, and indicate if changes were made. The images or other third party material in this article are included in the article's Creative Commons licence, unless indicated otherwise in a credit line to the material. If material is not included in the article's Creative Commons licence and your intended use is not permitted by statutory regulation or exceeds the permitted use, you will need to obtain permission directly from the copyright holder. To view a copy of this licence, visit http://creativecommons.org/licenses/by/4.0/ The Creative Commons Public Domain Dedication waiver (http://creativecommons.org/publicdomain/zero/1.0/) applies to the data made available in this article, unless otherwise stated in a credit line to the data. 
(Continued from previous page)

Conclusion: This pilot study in an Asian cohort found that patients were able to regain AROM of shoulder after major breast surgery at post-operative week 6 but had a worse QuickDASH disability score, especially in the subgroup with ALND. Aggressive and early rehabilitation should be encouraged. However, a longer follow-up is required to evaluate long term functional outcomes.

Keywords: Breast surgery, Rehabilitation, Upper limb function,

\section{Background}

Breast cancer is the most common cancer and leading cause of death in women worldwide with an incidence of $24.2 \%$ in all diagnosed cancers and a mortality of $15.0 \%$ in 2018 [1]. It is also the most common cancer locally in Singapore, occurring in almost 1 in 3 diagnosed cancers in females [2]. Surgical options for breast cancer include breast-conserving surgery and mastectomy. When diagnosed in early stage, breast cancer surgery offers excellent oncological outcomes with a 5-year survival of up to $92.9 \%$ [3].

The role of rehabilitation and functional outcomes are however less studied in breast cancer surgery despite musculoskeletal complications such as pain, decreased joint mobility and reduced muscle strength being commonly reported after major breast surgery [4-6]. Metrics such as function, quality of life, psychosocial impact and satisfaction are also generally not assessed by many breast units in the world. A systematic review by Hidding et al. demonstrated significant upper limb functional impairments such as reduced range of motion and activities in daily living on long-term follow-up [7]. In addition, axillary lymph node dissection (ALND) has been demonstrated to be an additional risk factor for upper limb functional impairment [7].

Functional outcomes are of increasing importance in breast cancer as survival and prognosis for breast cancer is excellent and improving over the years [3]. With more than half of diagnosed breast cancers occurring in middle-aged women between the ages of 45 and 64 years [2], it is pertinent to ensure preservation of upper limb function as this group of patients may be the main caregivers of their families, engage in an active lifestyle and at the peak of their careers.

Several studies have discussed about the importance of rehabilitation post-surgery to achieve upper limb functional recovery [8-10]. It has been also suggested that early rehabilitation may reduce the onset of complications [11]. Most of the studies were performed in the Western population, but studies in the East have shown that Asians may differ with higher body fat percentage, lower bone mass and lower level of physical activity [12-14]. These factors may influence the functional outcomes in patients with breast cancer. This study aims to evaluate whether major breast surgery results in functional impairment in a cohort of Asian women with breast cancer.

\section{Methods}

This is a single center prospective cohort study conducted at a university-affiliated teaching hospital. Patients were recruited between April 2018 to August 2019 with a follow-up of 6 weeks post-surgery. Main inclusion criteria were patients who were over 21 years of age undergoing major breast surgery for breast cancer. Major breast surgery was defined as wide local excision (WLE) or mastectomy performed for patients with diagnosed breast cancer. Main exclusion criteria were patients with pre-existing neurological or rheumatological co-morbidities affecting upper limb function or previous trauma with resulting deformities to the upper limbs. Patients who underwent mastectomy with reconstruction were also excluded. A total of 50 patients were recruited for this study and 9 patients were excluded from the final analysis (Fig. 1). Reasons for exclusion were described in Fig. 1. This study was approved by a local institutional review board (Ref: 2018/00156). All patients involved in the study provided written informed consent. The study protocol is shown in Fig. 1.

Patients were assessed in our outpatient one-stop breast clinic and underwent triple assessment with (1) clinical assessment, (2) radiological assessment with mammogram and breast ultrasound and (3) preoperative biopsy. Patients with breast cancer confirmed histologically were staged and discussed in the multi-disciplinary breast tumour board prior to surgery. Informed consent was taken by the surgeons in the breast specialist outpatient clinic for participation in the study. All patients were placed on standardised post-operative care pathway. Patients who underwent WLE were discharged as day surgery, while patients who underwent mastectomy were discharged on postoperative day 1. Patients who received mastectomy were discharged with a drain placed at the chest wall that was removed in the outpatient clinic within a week. Patients who had axillary clearance had additional drain placed in the axilla which was similarly removed within a week. Post-operative analgesia was 


\section{Study Protocol}

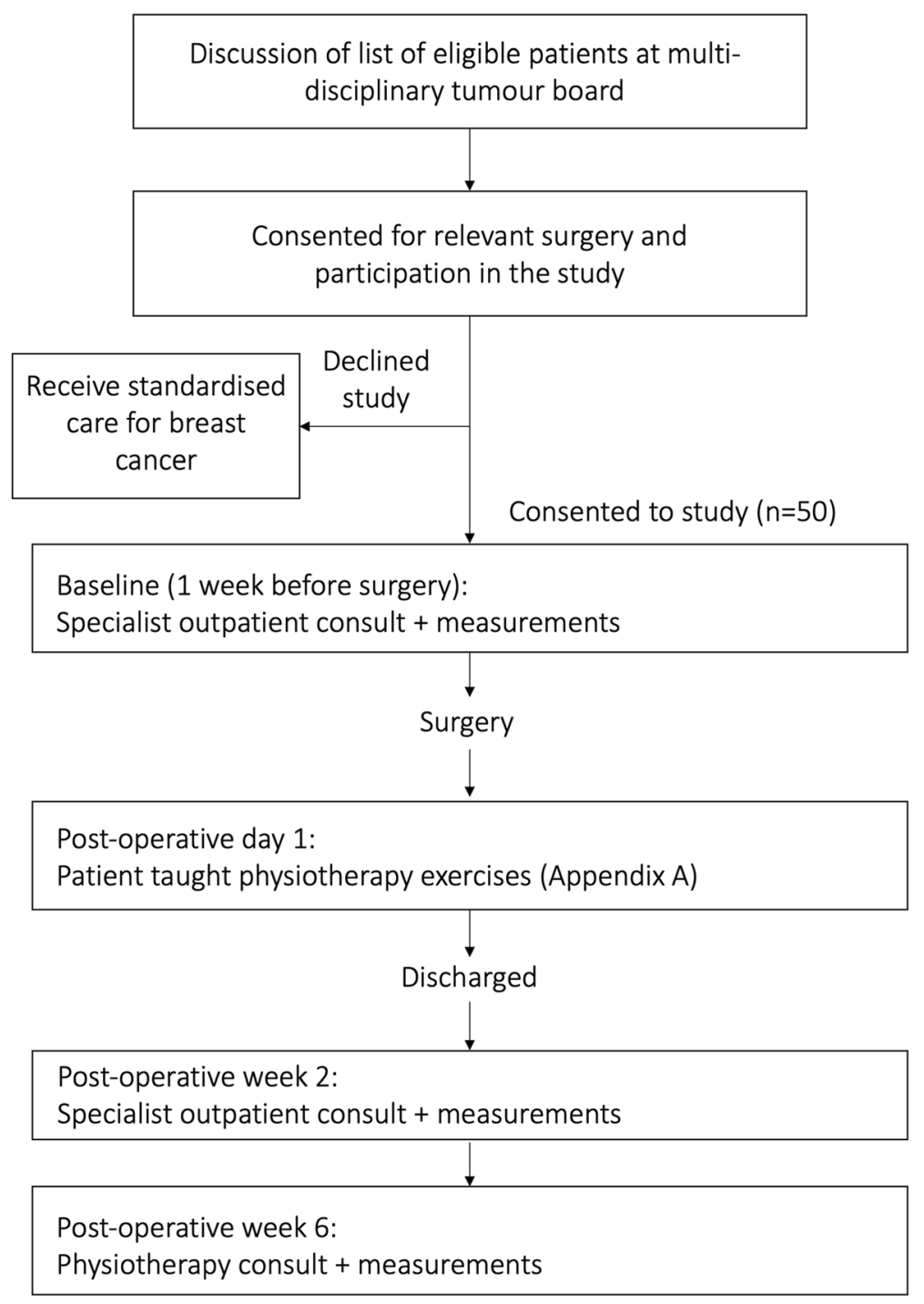

41 with 44 major breast surgeries included in final analyses

9 Excluded

1 stroke post-operatively

1 did not undergo surgery and sought second opinion

7 defaulted appointment as they felt they have recovered

Fig. 1 Study protocol outlining the conduct of this research study

standardised with paracetamol and non-steroidal inflammatory drugs for a duration of 1 week.

Upper limb function was assessed via measurement of shoulder flexion and abduction active range of motion (AROM) using a goniometer (12" Protractor Goniometer, Model 64, Prestige Medical, USA) (Fig. A.1, Table A.1) and completion of the QuickDASH questionnaire (Table B.1).
The QuickDASH questionnaire is a quick 11-point questionnaire which assesses subjective physical function and extent of symptoms [15]. The QuickDASH disability score was calculated upon completion of the questionnaire. Upper limb AROM measurements were performed by a dedicated breast care nurse and physiotherapist with formal 
standardization training session (Fig. A.1, Table A.1) conducted for both individuals prior to the start of the study.

Shoulder AROM and QuickDASH scores were assessed three times during the course of the study: (1) one week prior to surgery to assess patient's baseline function in the specialist outpatient clinic, (2) 2 weeks post-operative in the follow-up outpatient clinic and (3) 6 weeks post-operative at the physiotherapy clinic.

\section{Rehabilitation regime}

Patients were taught and prescribed a standardized set of shoulder and upper limb exercises immediately postsurgery or on post-operative day 1 prior to discharge (Table C.1) and were instructed to perform the exercises daily at home. Patients were assessed for compliance to the rehabilitation programme at 2 weeks and reiterations of exercises were made. The detailed post-rehabilitation protocol is shown in Table C.2.

\section{Surgical technique of axillary lymph node dissection}

The patient was positioned supine with her arms extended on an arm board at $\leq 90$ degrees abduction from the chest wall.

Axillary lymph node dissection was performed through the same incision for patients with modified radical mastectomy. A separate $4 \mathrm{~cm}$ incision was made in the axilla, two finger breadths below the hair bearing skin and perpendicular to the lateral edge of the pectoralis major for patients with WLE.

During ALND, the anatomical boundaries were first defined. The lateral edge of the pectoralis major muscle was identified and retracted medially to expose the pectoralis minor muscle and allow interpectoral dissection of Rotter's lymph nodes. The medial pectoral neurovascular bundle was preserved during the dissection. The clavipectoral fascia was entered and axillary fat pad along lateral chest wall was dissected. Long thoracic nerve along the lateral chest wall was identified and preserved. Next, the latissimus dorsi border was identified. Dissection along the latissimus dorsi border was extended inferiorly until the muscle begun to pull toward the chest wall and superiorly to the tendon of insertion

Dissection proceeded superiorly till the axillary vein was identified. The thoracodorsal bundle was identified and preserved before mobilization of the axillary fat pad and dissection off the chest wall and the inferior surface of the axillary vein and off the thoracodorsal bundle posteriorly. The intercostobrachial nerve was preserved if possible but small branches running through the axilla fat pad that cannot be spared were ligated.
Table 1 Patient demographics and clinical profile

\begin{tabular}{ll}
\hline & $N=44(\%)$ \\
\hline Age, median (IQR) & $62.5(53.3-65)$ \\
Gender, female & $44(100)$ \\
Co-morbidities & \\
Diabetes mellitus & $10(22.7)$ \\
Chronic kidney disease & $2(4.5)$ \\
Ischemic heart disease & $2(4.5)$ \\
Previous breast surgery & $2(4.5)$ \\
Clinical presentation & \\
Asymptomatic (detected on screening) & $12(27.3)$ \\
Breast mass & $29(65.9)$ \\
Nipple discharge & $2(4.5)$ \\
Mastalgia & $2(4.5)$ \\
Axillary lymphadenopathy (clinical) & $4(9.1)$ \\
Type of major breast surgery & \\
Wide local excision & $16(36.4)$ \\
$\quad$ With SLNB & $16(100)$ \\
With ALND & $5(31.3)$ \\
Simple mastectomy & $28(63.6)$ \\
With SLNB & $27(96.4)$ \\
With ALND & $10(35.7)$ \\
Neoadjuvant chemotherapy & $4(9.1)$ \\
Iymph Axillary lymph node dissection, IQR Interquartile range, SLNB Sentinel & \\
\hline &
\end{tabular}

\section{Data collection}

Patient demographics and intra-operative records were collected from the hospital electronic medical records. Patients who defaulted any of the follow-up appointments were contacted by the study administrator via phone interview to ascertain the reason for defaulting.

Table 2 Operative and histopathological details

\begin{tabular}{ll}
\hline & $N=44(\%)$ \\
\hline Sentinel lymph node biopsy & $43(97.9)$ \\
Axillary lymph node dissection & $15(34.1)$ \\
Oncoplastic procedure performed during & $1(6.3)^{\mathrm{b}}$ \\
breast conserving surgery & \\
Diagnosis ${ }^{\mathrm{a}}, \mathrm{n}(\%)$ & \\
$\quad$ DCIS & $2(4.7)$ \\
$\quad$ Invasive carcinoma & $41(95.3)$ \\
Size of tumour (cm), median (IQR) & $2.2(1.5-3.5)$ \\
Seroma or haematoma & $17(38.6)$ \\
\hline
\end{tabular}

IQR Interquartile range

${ }^{a}$ One of the major breast surgeries was done prophylactically with presence of tumour only on the contralateral side, hence $n=43$ for this case

${ }^{b}$ Expressed as over number of patients who underwent breast conserving surgery 
Table 3 Upper limb function of all patients who underwent major breast surgery

\begin{tabular}{|c|c|c|c|c|c|c|c|c|c|c|c|c|}
\hline & Total $(n=$ & 44) & & & $\operatorname{ALND}(n=$ & 15) & & & No ALND & $(n=29)$ & & \\
\hline & Baseline & $\begin{array}{l}\text { Post- } \\
\text { operative } \\
\text { week } 2\end{array}$ & $\begin{array}{l}\text { Post- } \\
\text { operative } \\
\text { week } 6\end{array}$ & $\begin{array}{l}p^{-} \\
\text {value }^{*}\end{array}$ & Baseline & $\begin{array}{l}\text { Post- } \\
\text { operative } \\
\text { week } 2\end{array}$ & $\begin{array}{l}\text { Post- } \\
\text { operative } \\
\text { week } 6\end{array}$ & $\begin{array}{l}p^{-} \\
\text {value }^{*}\end{array}$ & Baseline & $\begin{array}{l}\text { Post- } \\
\text { operative } \\
\text { week } 2\end{array}$ & $\begin{array}{l}\text { Post- } \\
\text { operative } \\
\text { week } 6\end{array}$ & $\begin{array}{l}p- \\
\text { value }\end{array}$ \\
\hline $\begin{array}{l}\text { Shoulder } \\
\text { flexion } \operatorname{AROM}^{+}\left({ }^{\circ}\right)\end{array}$ & $\begin{array}{l}160 \\
(150- \\
170)\end{array}$ & $\begin{array}{l}155 \\
(150-165)\end{array}$ & $\begin{array}{l}160 \\
(146-170)\end{array}$ & 0.775 & $\begin{array}{l}165 \\
(150-170)\end{array}$ & $\begin{array}{l}159 \\
(153-170)\end{array}$ & $\begin{array}{l}160(145- \\
170)\end{array}$ & 0.551 & $\begin{array}{l}158 \\
(148-166)\end{array}$ & $\begin{array}{l}155 \\
(149-160)\end{array}$ & $\begin{array}{l}160 \\
(148-170)\end{array}$ & 0.319 \\
\hline $\begin{array}{l}\text { Shoulder } \\
\text { abduction } \\
\operatorname{AROM}^{+}\left({ }^{\circ}\right)\end{array}$ & $\begin{array}{l}157 \\
(150- \\
171)\end{array}$ & $\begin{array}{l}159 \\
(143-169)\end{array}$ & $\begin{array}{l}175 \\
(155-180)\end{array}$ & 0.016 & $\begin{array}{l}160 \\
(152-173)\end{array}$ & $\begin{array}{l}165 \\
(146-171)\end{array}$ & $\begin{array}{l}175(170- \\
180)\end{array}$ & 0.443 & $\begin{array}{l}154 \\
(147-165)\end{array}$ & $\begin{array}{l}159 \\
(143-165)\end{array}$ & $\begin{array}{l}172 \\
(155-180)\end{array}$ & 0.014 \\
\hline Pain score ${ }^{+\#}$ & $1(1-1)$ & $1(1-2)$ & $1(1-2)$ & 0.054 & $1(1-1)$ & $2(1-2)$ & $1(1-2)$ & 0.102 & $1(1-1)$ & $1(1-2)$ & $1(1-2)$ & 0.198 \\
\hline $\begin{array}{l}\text { Numbness } \\
\text { score }^{+\#}\end{array}$ & $1(1-1)$ & $1(1-2)$ & $1(1-2)$ & 0.072 & $1(1-1)$ & $2(1-2)$ & $2(1-2)$ & 0.166 & $1(1-1)$ & $1(1-2)$ & $1(1-2)$ & 0.248 \\
\hline $\begin{array}{l}\text { QuickDASH } \\
\text { disability score }\end{array}$ & $\begin{array}{l}0(0- \\
4.03)\end{array}$ & $\begin{array}{l}6.82 \\
(2.27-13.64)\end{array}$ & $\begin{array}{l}2.5 \\
(0-8.52)\end{array}$ & 0.027 & $\begin{array}{l}2.27 \\
(0-2.5)\end{array}$ & $\begin{array}{l}6.82 \\
(2.27-15)\end{array}$ & $\begin{array}{l}5.0 \\
(2.27-9.09)\end{array}$ & 0.010 & $0(0-5.0)$ & $\begin{array}{l}6.82 \\
(2.27-13.64)\end{array}$ & $\begin{array}{l}2.27 \\
(0-6.82)\end{array}$ & 0.396 \\
\hline
\end{tabular}

ALND Axillary lymph node dissection, AROM Active range of motion

${ }^{+}$All of the study variables in this table are presented in median (IQR) unless otherwise specified

${ }^{*} p$-value is obtained by performing a Wilcoxon-signed rank test comparing baseline and post-operative week 6 values

\#Pain score and numbness score are components of the QuickDASH questionnaire ranging from 1 to 5 , where 1 represents none, 2 represents mild, 3 represents

moderate, 4 represents severe and 5 represents extreme

\section{Study outcomes}

Primary study outcomes were AROM of shoulder flexion and abduction and QuickDASH disability score (Table B.1). Secondary outcomes were arm pain and numbness scores derived from the QuickDASH questionnaire.

\section{Statistical analysis}

All the data were tabulated into a Microsoft Excel sheet and transposed into SPSS version 25.0 (SPSS Inc., Chicago, III., USA) for statistical analyses. All continuous data were expressed as mean or median and analysed by Wilcoxon-signed rank test or MannWhitney $U$ test. All categorical variables were described as percentage and compared by either chi-squared or Fisher's exact test. $P$-value $<0.05$ was considered statistically significant.

\section{Results}

A total of 50 patients were recruited for this study and 9 patients were excluded from the final analysis (Fig. 1). Forty-one patients who underwent 44 major breast surgeries were included in the analysis. Three patients had bilateral major breast surgeries, of which, two had a)

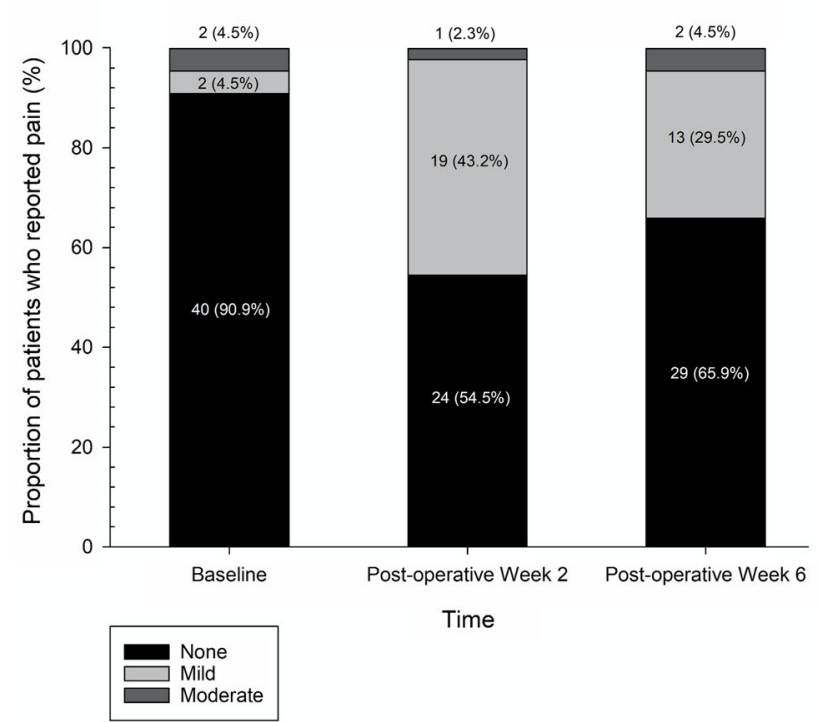

b)

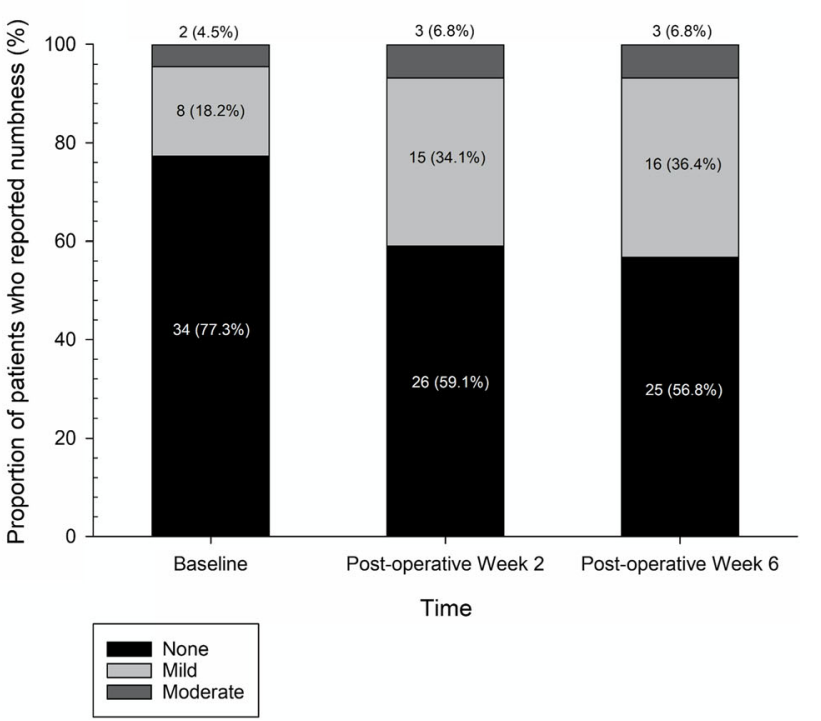

Fig. 2 Severity of (a) pain and (b) numbness reported at baseline, post-operative week 2 and post-operative week 6 

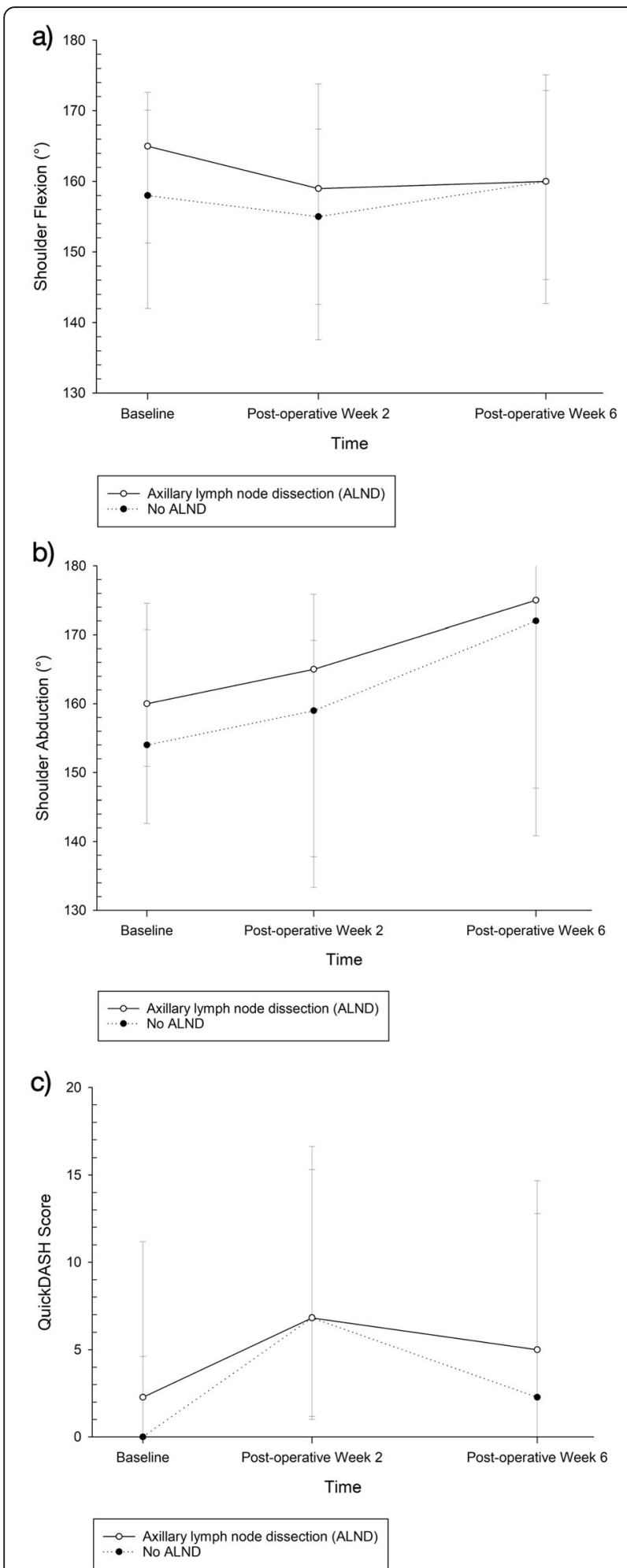

Fig. 3 Changes in (a) shoulder flexion (b) shoulder abduction and (c) quickDASH disability score at baseline, post-operative week 2 and post-operative week 6 in the axillary lymph node dissection (ALND) and no ALND subgroup bilateral breast cancer, and one underwent a right mastectomy for breast cancer with prophylactic left mastectomy as requested by the patient. There were no nerve injuries to brachial plexus, long thoracic nerve, thoracodorsal and medial pectoral neurovascular bundle in our study. Patient demographics are summarized in Table 1. Operative and histopathological details are summarized in Table 2.

Table 3 summarizes the shoulder flexion and abduction AROM, pain score, numbness score and QuickDASH disability score of all the included cases preoperatively, post-operative week 2 and post-operative week 6. Components of the QuickDASH disability score are shown in Table B.1 (Appendix B). Figure 2a and b represents the severity of pain and numbness reported at different time intervals of the study.

Subgroup analysis of patients with ALND demonstrated significantly worse QuickDASH disability score at post-operative week 6 compared to baseline $(p=$ 0.010) (Table 3). However, patients with only sentinel lymph node biopsy (SLNB) without ALND had comparable QuickDASH disability score at post-operative week 6 compared to baseline $(p=0.396)$. Figure $3 \mathrm{a}$ and $\mathrm{b}$ and $c$ are pictorial representations of the change in shoulder flexion, abduction and quickDASH disability score in the ALND versus no ALND subgroup.

Table 4 summarises the upper limb function of patients with wide local excision with SLNB compared to mastectomy with SLNB. Shoulder flexion and abduction at post-operative week 2 is significantly lower in the group with mastectomy $(p=0.018$ and $p=0.012$ respectively), and also at post-operative week $6(p=0.019$ and $p=0.008$ respectively). Table 5 summarises the upper limb function of patients with wide local excision with ALND compared to mastectomy with ALND. Shoulder flexion in the mastectomy subgroup is significantly lower at post-operative week 6 .

\section{Discussion}

There has been increasing interest in functional outcomes after cancer surgery in the surgical community [16]. This is especially relevant for surgeries with high fidelity, excellent surgical and oncological outcomes such as breast cancer surgery [3]. In this group of patients, the next focus is to improve on overall holistic care and to ensure that they return back to baseline function. Functional decline of the upper limb after major breast surgery has been reported not infrequently and this is one of the first studies to our knowledge to examine this phenomenon in the Asian population [4-7].

Our unit adopts an early and aggressive rehabilitation regime which encourages patients to start mobilizing and perform upper limb exercises in their homes from the first post-operative day. Objectively, this pilot study 
Table 4 Comparison of wide local excision (WLE) with sentinel lymph node biopsy (SLNB) versus mastectomy with SLNB

\begin{tabular}{|c|c|c|c|c|c|c|c|c|c|}
\hline & \multicolumn{3}{|l|}{ Baseline } & \multicolumn{3}{|c|}{ Post-operative week 2} & \multicolumn{3}{|c|}{ Post-operative week 6} \\
\hline & $\begin{array}{l}\mathrm{WLE}+\mathrm{SLNB} \\
(n=16)\end{array}$ & $\begin{array}{l}\text { Mastectomy + } \\
\text { SLNB }(n=27)\end{array}$ & $\begin{array}{l}p^{-} \\
\text {value }\end{array}$ & $\begin{array}{l}\mathrm{WLE}+\mathrm{SLNB} \\
(n=16)\end{array}$ & $\begin{array}{l}\text { Mastectomy + } \\
\text { SLNB }(n=27)\end{array}$ & $\begin{array}{l}p^{-} \\
\text {value }^{*}\end{array}$ & $\begin{array}{l}\mathrm{WLE}+\mathrm{SLNB} \\
(n=16)\end{array}$ & $\begin{array}{l}\text { Mastectomy + } \\
\text { SLNB }(n=27)\end{array}$ & $\begin{array}{l}p- \\
\text { value }\end{array}$ \\
\hline Shoulder flexion $\operatorname{AROM}^{+}\left({ }^{\circ}\right)$ & $166(151-171)$ & $158(148-165)$ & 0.127 & $160(155-167)$ & $154(140-159)$ & 0.018 & $170(160-174)$ & $155(142-170)$ & 0.019 \\
\hline Shoulder abduction $\operatorname{AROM}^{+}\left({ }^{\circ}\right)$ & $165(152-173)$ & $154(145-165)$ & 0.173 & $165(159-170)$ & $148(133-167)$ & 0.012 & $180(175-180)$ & $170(145-180)$ & 0.008 \\
\hline Pain score ${ }^{+\#}$ & $1(1-1)$ & $1(1-1)$ & 0.583 & $1(1-2)$ & $1(1-2)$ & 0.452 & $1(1-2)$ & $1(1-2)$ & 0.771 \\
\hline Numbness score ${ }^{+\#}$ & $1(1-2)$ & $1(1-1)$ & 0.442 & $1(1-2)$ & $1(1-2)$ & 0.103 & $1(1-2)$ & $2(1-2)$ & 0.040 \\
\hline QuickDASH disability score ${ }^{+}$ & $2.27(0-5)$ & $0(0-2.5)$ & 0.493 & $4.77(0-13.07)$ & $6.81(2.5-13.6)$ & 0.158 & $4.77(0-8.52)$ & $2.27(0-9.09)$ & 0.699 \\
\hline
\end{tabular}

AROM Active range of motion, WLE Wide local excision

${ }^{+}$All of the study variables in this table are presented in median (IQR) unless otherwise specified

" $p$-value is obtained by performing a Mann-Whitney $\mathrm{U}$ test comparing between the two groups at a specific time interval (baseline, post-operative week 2 or postoperative week 6)

"Pain score and numbness score are components of the QuickDASH questionnaire ranging from 1 to 5 , where 1 represents none, 2 represents mild, 3 represents moderate, 4 represents severe and 5 represents extreme

demonstrated return to baseline function in shoulder AROM at 6 weeks post-operative. Gosselink et al. who described good functional recovery at 3 months also adopted a similar early rehabilitation regime from postoperative day 2 in their centre [10]. This is in contrast to other studies who reported significant residual functional impairment whose rehabilitation regime are only commenced at 2 weeks to 1 month postoperative $[11,17]$. Delayed stretching and rehabilitation may be less effective as scar tissue become denser and are less receptive to short-term stretching $[18,19]$. However, it is also worth noting that a study by Scaffidi et al. which compared early and delayed rehabilitation showed no difference in shoulder impairment at post-operative day 60 [11].

Interestingly, our study showed an improvement in shoulder abduction at post-operative week 6 compared to baseline (post-operative week $6 \mathrm{AROM} 175^{\circ}$ vs baseline AROM $157^{\circ}, p=0.016$ ). This phenomenon has been demonstrated in another study by Beurskens et al. who demonstrated an increase in shoulder flexion and abduction AROM from baseline after physiotherapy post breast surgery and axillary dissection [9]. We postulate that some patients may have impaired upper limb function pre-operatively either from pain or axilla lymph node disease that benefited from surgery and an aggressive post-operative rehabilitation regime.

Despite demonstrating objective return of shoulder AROM back to baseline, our study found a significantly worse QuickDASH disability score at post-operative week 6 (median score 2.5, IQR 0-8.52, $p=0.027$ ) compared to baseline. We postulate that this phenomenon may be contributed by the presence of pain and numbness in the upper limb despite regaining AROM. A possible consideration will be to extend the duration of rehabilitation with an existing study by Beurskens et al. reporting a significant improvement in pain following physiotherapy at 3 months [9]. However in the era where value based care is a buzz word in Singapore, cost effectiveness of such an approach is debatable.

Table 5 Comparison of wide local excision (WLE) with axillary lymph node dissection (ALND) versus mastectomy with ALND

\begin{tabular}{|c|c|c|c|c|c|c|c|c|c|}
\hline & \multicolumn{3}{|l|}{ Baseline } & \multicolumn{3}{|c|}{ Post-operative week 2} & \multicolumn{3}{|c|}{ Post-operative week 6} \\
\hline & $\begin{array}{l}\text { WLE + ALND } \\
(n=5)\end{array}$ & $\begin{array}{l}\text { Mastectomy + } \\
\text { ALND }(n=10)\end{array}$ & $\begin{array}{l}p- \\
\text { value }^{*}\end{array}$ & $\begin{array}{l}\text { WLE + ALND } \\
(n=5)\end{array}$ & $\begin{array}{l}\text { Mastectomy + } \\
\text { ALND }(n=10)\end{array}$ & $\begin{array}{l}p^{-} \\
\text {value }\end{array}$ & $\begin{array}{l}\text { WLE }+ \text { ALND } \\
(n=5)\end{array}$ & $\begin{array}{l}\text { Mastectomy }+ \\
\text { ALND }(n=10)\end{array}$ & $\begin{array}{l}p- \\
\text { value }\end{array}$ \\
\hline $\begin{array}{l}\text { Shoulder flexion } \\
\operatorname{AROM}^{+}\left({ }^{\circ}\right)\end{array}$ & $166(153-174)$ & $163(150-170)$ & 0.679 & $165(160-172)$ & $155(145-170)$ & 0.254 & $170(165-178)$ & $155(142-161)$ & 0.019 \\
\hline $\begin{array}{l}\text { Shoulder abduction } \\
\operatorname{AROM}^{+}\left({ }^{\circ}\right)\end{array}$ & $171(152-174)$ & $160(154-174)$ & 0.953 & $170(166-176)$ & $148(121-170)$ & 0.055 & $180(173-180)$ & 175 (130-180) & 0.310 \\
\hline Pain score ${ }^{+\#}$ & $1(1-1.5)$ & $1(1-1)$ & 0.768 & $1(1-2)$ & $2(1-2)$ & 0.513 & $1(1-1.5)$ & $1.5(1-2)$ & 0.371 \\
\hline Numbness score ${ }^{+\#}$ & $1(1-2)$ & $1(1-1.3)$ & 0.679 & $2(1-2)$ & $2(1-2)$ & 0.679 & $1(1-1.5)$ & $2(1.8-2)$ & 0.055 \\
\hline $\begin{array}{l}\text { QuickDASH disability } \\
\text { score }^{+}\end{array}$ & $2.27(0-3.64)$ & $1.14(0-3.01)$ & 0.953 & $5.00(1.14-15.00)$ & $8.41(2.44-14.60)$ & 0.679 & $5.00(1.14-7.95)$ & $5.68(2.27-15.23)$ & 0.513 \\
\hline
\end{tabular}

AROM Active range of motion, ALND Axillary lymph node dissection

${ }^{+}$All of the study variables in this table are presented in median (IQR) unless otherwise specified

${ }^{*} p$-value is obtained by performing a Mann-Whitney $U$ test comparing between the two groups at a specific time interval (baseline, post-operative week 2 or postoperative week 6)

\#Pain score and numbness score are components of the QuickDASH questionnaire ranging from 1 to 5 , where 1 represents none, 2 represents mild, 3 represents moderate, 4 represents severe and 5 represents extreme 
The question of which is the best measurement of upper limb function is still unanswered as various studies have reported heterogenous upper limb outcome measures which include shoulder mobility, pain intensity, presence of lymphedema and assessment of activities of daily living $[10,20]$. We used the quickDASH disability score for the study as it is a simple patient reported 11-point questionnaire which assesses subjective physical function, important symptoms such as pain and numbness and its impact on daily activities [15]. This may be more holistic compared to earlier studies which solely evaluate symptoms without assessment of impact on daily activities. We believe the use of both AROM and quickDASH disability score in our study allows a standardized holistic assessment of the overall function of the patient.

Subgroup analysis of patients with and without ALND (Table 3) demonstrated worse QuickDASH disability score at post-operative week 6 compared to baseline only for patients with ALND. This is consistent with findings from Western studies as ALND is a known predictor of short-term upper limb morbidity [7, 21]. However, our subgroup analysis showed superior results for patients who only had SLNB without ALND as compared to the study by Rietman et al. on 204 patients, which demonstrated significant decrease in shoulder AROM at post-operative week 6 following SLNB [21]. Similarly, we believe that early rehabilitation may be the contributing factor to our favourable results.

Our study also demonstrated worse upper limb function at 6 weeks for mastectomy compared to WLE regardless of whether SLNB or axillary clearance was performed. This finding is consistent with a systematic review by Lee et al. who demonstrated mastectomy as a risk factor for reduced shoulder range of motion compared to breast-conserving surgery (OR 5.67, 95\% CI 1.03-31.16) [22]. This information deserves to be highlighted to the patient during pre-operative counselling and taken into consideration during informed consent since the outcome impacts on function and quality of life. This also reinforces the importance of rehabilitation after mastectomy especially those who received ALND, as the risk of lymphoedema can be minimized which improves eventual upper limb function.

One of the limitations is the relatively small sample size in this pilot study. However, it has been welldescribed in literature that a minimum of 10-12 patients in a pilot study provides the ability to test a hypothesis $[23,24]$. We are also unable to enforce compliance as the exercises were performed in the patient's home. However, prior to discharge, the physiotherapist will conduct a dedicated session with the aid of pamphlets for the patient and educate them on the importance of following the exercise regime strictly and will further reinforce this information at the 2 weeks follow-up appointment. Lastly, the follow-up period in our study is relatively short and it is likely that patients' disability score may continue to improve after the 6 weeks.

\section{Conclusions}

This pilot study in an Asian cohort found that patients were able to regain AROM of shoulder after major breast surgery at post-operative week 6 but had a worse QuickDASH disability score, especially in the subgroup with ALND. Aggressive and early rehabilitation should be encouraged. However, a longer follow-up is required to evaluate long term functional outcomes.

\section{Supplementary information}

Supplementary information accompanies this paper at https://doi.org/10. 1186/s12893-020-00773-0.

Additional file 1: Appendix A. Measurement of shoulder range of motion. Figure A.1. Pictorial representation of measurement of shoulder range of motion using a goniometer. Written consent has been obtained from both of the people included in the figure. Table A.1. Measurement of shoulder range of motion using a goniometer. Appendix B: Details of the QuickDASH Questionnaire. Table B.1. Components of the QuickDASH Questionnaire. Table B.2. Breakdown of components of the QuickDASH questionnaire. Appendix C: Physiotherapy exercises. Table C.1. List of physiotherapy exercises prescribed for patients post-major breast surgery. Table C.2. Post-operative rehabilitation protocol

\section{Abbreviations}

ALND: Axillary lymph node dissection; AROM: Active range of motion; WLE: Wide local excision

\section{Acknowledgements}

We would like to thank Ms. Nur Amalina Binti Sapuan from the Department of Physiotherapy of Khoo Teck Puat Hospital for her participation in the study and consent for the use of Fig. A.1. We would also like to thank Miss Lih Yen $\mathrm{Ng}$, Head of Department of Physiotherapy for assisting in the rehabilitation programme.

\section{Authors' contributions}

All authors have read and approved the manuscript in its current state. KSC obtained funding, analysed the data and wrote the manuscript. DZ collected the data and wrote the manuscript. JHTL, BSYO, KTK and YHY collected the data. JTTG conceptualized the study and recruited the patients. CLKC conceptualized the study, obtained the funding, supervised the study, wrote and amended the manuscript.

\section{Funding}

This work was supported by the Alexandra Health Enabling Grant FY2018 (Grant number: AHEG1816). The funding body had no role in the design of the study and collection, analysis, interpretation of data or writing of the manuscript.

\section{Availability of data and materials}

The datasets used and/or analysed during the current study are available from the corresponding author on reasonable request.

\section{Ethics approval and consent to participate}

This study was approved by the National Healthcare Group Domain Specific Review Board (Ref: 2018/00156). All patients involved in the study provided written informed consent. 


\section{Consent for publication}

The participants included in Fig. A.1 consent to the use of the photo for publication purposes. A written consent was obtained.

\section{Competing interests}

The authors declare that they have no competing interests.

\section{Author details}

${ }^{1} \mathrm{MOH}$ Holdings Pte Ltd, Singapore, Singapore. ${ }^{2}$ Lee Kong Chian School of Medicine, Nanyang Technological University, Singapore, Singapore.

${ }^{3}$ Department of General Surgery, Khoo Teck Puat Hospital, Singapore, Singapore. ${ }^{4}$ Department of Physiotherapy, Khoo Teck Puat Hospital, Singapore, Singapore.

Received: 4 March 2020 Accepted: 11 May 2020

Published online: 19 May 2020

\section{References}

1. Bray F, Ferlay J, Soerjomataram I, Siegel RL, Torre LA, Jemal A. Global cancer statistics 2018: GLOBOCAN estimates of incidence and mortality worldwide for 36 cancers in 185 countries. CA Cancer J Clin. 2018;68(6):394-424.

2. Singapore Cancer Registry. Singapore Cancer Registry Annual Registry Report 2015 2015. Available from: https://www.nrdo.gov.sg/docs/ librariesprovider3/Publications-Cancer/cancer-registry-annual-report-2015 web.pdf?sfvrsn=10. Accessed 16 Feb 2020.

3. Onitilo AA, Engel JM, Stankowski RV, Doi SA. Survival comparisons for breast conserving surgery and mastectomy revisited: community experience and the role of radiation therapy. Clin Med Res. 2015;13(2):65-73.

4. Tsai RJ, Dennis LK, Lynch CF, Snetselaar LG, Zamba GK, Scott-Conner C. The risk of developing arm lymphedema among breast cancer survivors: a meta-analysis of treatment factors. Ann Surg Oncol. 2009;16(7):1959-72.

5. Rietman JS, Geertzen J, Hoekstra H, Baas P, Dolsma W, De Vries J, et al. Long term treatment related upper limb morbidity and quality of life after sentinel lymph node biopsy for stage I or II breast cancer. Eur J Surg Oncol (EJSO), 2006:32(2):148-52

6. Land SR, Kopec JA, Julian TB, Brown AM, Anderson SJ, Krag DN, et al. Patient-reported outcomes in sentinel node-negative adjuvant breast cancer patients receiving sentinel-node biopsy or axillary dissection: National Surgical Adjuvant Breast and bowel project phase III protocol B-32. J Clin Oncol. 2010;28(25):3929.

7. Hidding JT, Beurskens $\mathrm{CH}$, van der Wees PJ, van Laarhoven HW. Nijhuis-van der Sanden MW. Treatment related impairments in arm and shoulder in patients with breast cancer: a systematic review. PloS one. 2014;9(5):e96748.

8. McLaughlin SA, Wright MJ, Morris KT, Giron GL, Sampson MR, Brockway JP, et al. Prevalence of lymphedema in women with breast cancer 5 years after sentinel lymph node biopsy or axillary dissection: objective measurements. $J$ Clin Oncol. 2008;26(32):5213.

9. Beurskens $\mathrm{CH}$, van Uden CJ, Strobbe $\amalg$, Oostendorp RA, Wobbes T. The efficacy of physiotherapy upon shoulder function following axillary dissection in breast cancer, a randomized controlled study. BMC Cancer. 2007;7(1):166

10. Gosselink R, Rouffaer L, Vanhelden P, Piot W, Troosters T, Christiaens MR. Recovery of upper limb function after axillary dissection. J Surg Oncol. 2003; 83(4):204-11.

11. Scaffidi M, Vulpiani M, Vetrano M, Conforti $F$, Marchetti M, Bonifacino A, et al. Early rehabilitation reduces the onset of complications in the upper limb following breast cancer surgery. Eur J Phys Rehabil Med. 2012;48(4): 601-11.

12. Deurenberg-Yap M, Schmidt G, van Staveren WA, Deurenberg P. The paradox of low body mass index and high body fat percentage among Chinese, Malays and Indians in Singapore. Int J Obes. 2000;24(8):1011-7.

13. Ho SC, Hsu SY, Leung PC, Chan C, Swaminathan R, Fan YK, et al. A longitudinal study of the determinants of bone mass in Chinese women aged 21 to 40 I. baseline association of anthropometric measurements with bone mineral density. Ann Epidemiol. 1993;3(3):256-63.

14. Fischbacher C, Hunt S, Alexander L. How physically active are south Asians in the United Kingdom? A literature review. J Public Health. 2004;26(3):250-8.

15. Gummesson C, Ward MM, Atroshi I. The shortened disabilities of the arm, shoulder and hand questionnaire (quick DASH): validity and reliability based on responses within the full-length DASH. BMC Musculoskelet Disord. 2006; 7(1):44.
16. Chia CL, Mantoo S, Tan K. 'Start to finish trans-institutional transdisciplinary care': a novel approach improves colorectal surgical results in frail elderly patients. Color Dis. 2016;18(1):043-50.

17. Devoogdt N, Van Kampen M, Christiaens M, Troosters T, Piot W, Beets N, et al. Short-and long-term recovery of upper limb function after axillary lymph node dissection. Eur J Cancer Care. 2011;20(1):77-86.

18. Houglum PA. Soft tissue healing and its impact on rehabilitation. J Sport Rehabil. 1992;1 (1):19-39.

19. Stanish W, Curwin S, Brysoln G. The use of flexibility exercises in preventing and treating sports injuries. In: Leadbetter WB, Buckwalter JA, Gordon SL, editors. Sports-Induced Inflammation. Illinois: Amer Acad of Orthop Surgeons; 1989. p. 731-45.

20. Sagen A, Kaaresen R, Sandvik L, Thune I, Risberg MA. Upper limb physical function and adverse effects after breast cancer surgery: a prospective 2.5 year follow-up study and preoperative measures. Arch Phys Med Rehabil. 2014;95(5):875-81.

21. Rietman JS, Dijkstra PU, Geertzen JH, Baas P, De Vries J, Dolsma W, et al. Short-term morbidity of the upper limb after sentinel lymph node biopsy or axillary lymph node dissection for stage I or II breast carcinoma. Cancer. 2003;98(4):690-6.

22. Lee TS, Kilbreath SL, Refshauge KM, Herbert RD, Beith JM. Prognosis of the upper limb following surgery and radiation for breast cancer. Breast Cancer Res Treat. 2008;110(1):19-37.

23. Julious SA. Sample size of 12 per group rule of thumb for a pilot study. Pharm Stat J Appl Stat Pharm Ind. 2005;4(4):287-91.

24. Van Belle G. Statistical rules of thumb: John Wiley \& Sons; 2011.

\section{Publisher's Note}

Springer Nature remains neutral with regard to jurisdictional claims in published maps and institutional affiliations.

Ready to submit your research? Choose BMC and benefit from:

- fast, convenient online submission

- thorough peer review by experienced researchers in your field

- rapid publication on acceptance

- support for research data, including large and complex data types

- gold Open Access which fosters wider collaboration and increased citations

- maximum visibility for your research: over $100 \mathrm{M}$ website views per year

At $\mathrm{BMC}$, research is always in progress.

Learn more biomedcentral.com/submissions 